\begin{tabular}{|c|c|}
\hline Title & Hydrothermal synthesis and photocatalytic activities of stabilized bismuth vanadate/bismuth tungstate composites \\
\hline Author(s) & Ketwong, Pradudnet; T akashima, Mai; Nitta, A kio; Pookmanee, Pusit; Ohtani, Bunsho \\
\hline Citation & $\begin{array}{l}\text { Journal of environmental chemical engineering, 6(2), 2048 } 2054 \\
\text { https://doi.org/10.1016/j.jece.2018.01.062 }\end{array}$ \\
\hline Issue Date & $2018-04$ \\
\hline Doc URL & http:/hdl.handle.net/2115/77191 \\
\hline Rights & $\begin{array}{l}\text { (9 2018. This manuscript version is made available under the CC-BY -NC-ND } 4.0 \text { license } \\
\text { http://reativecommons.org/icenses/by-nc-nd/4.0/ }\end{array}$ \\
\hline Rights(URL) & http://creativecommons.org/icenses/by-nc-nd/4.0/ \\
\hline Type & article (author version) \\
\hline File Information & PKVWO.pdf \\
\hline
\end{tabular}

Instructions for use 


\title{
Hydrothermal synthesis and photocatalytic activities of stabilized bismuth vanadate/bismuth tungstate composites
}

\author{
Pradudnet Ketwong ${ }^{\mathrm{a},{ }^{*}}$, Mai Takashima ${ }^{\mathrm{b}, \mathrm{c}}$, Akio Nitta ${ }^{\mathrm{b}}$, Pusit Pookmanee ${ }^{\mathrm{a}}$, Bunsho Ohtani ${ }^{\mathrm{b}, \mathrm{c}}$ \\ ${ }^{a}$ Department of Chemistry, Faculty of Science, Maejo University, Chiang Mai, 50290, \\ Thailand \\ ${ }^{\mathrm{b}}$ Graduate School of Environmental Science, Hokkaido University, Sapporo, 060-0810, \\ Japan \\ c Institute for Catalysis, Hokkaido University, Sapporo, 001-0021, Japan
}

Keywords: Bismuth vanadate/bismuth tungstate, Photocatalyst, Stabilization, Photoacoustic spectroscopy

\begin{abstract}
Bismuth vanadate/bismuth tungstate (BVO/BWO) composites in various BVO fractions $(f(V))$ were synthesized through hydrothermal reaction. Morphology analysis of the composites showed that rod-like BVO structures were partially deposited on flake-ball (FB) BWO particles. In addition, surface structures of BWO, BVO and BVO/BWO were studied in energy-resolved distribution of electron traps and conduction band-bottom (CBB) position by household reversed double-beam photoacoustic spectroscopy (PAS) and single-beam PAS, respectively. Apparent $\mathrm{CBB}$ of $\mathrm{BVO} / \mathrm{BWO}$ was ca. $0.4 \mathrm{eV}$ anodically shifted from BWO and almost similar to BVO. Moreover, photocatalytic oxygen liberation under irradiation of UVvis and visible lights demonstrated that photocatalytic activities of the BVO/BWO composites were depended on $f(\mathrm{~V})$ and calcined BVO/BWO composites in which BVO was stabilized on BWO showed enhancement of photocatalytic activity comparing to a pristine BVO. The prolonged and the highest active photocatalyst under visible light was calcined $0.80 f(\mathrm{~V})$ due to BVO stabilization on FB-BWO particles.
\end{abstract}

\section{Introduction}

Photocatalysts used for solar photocatalysis, which is a photochemical reaction, have been developed for environmental treatment applications and energy production [1-4]. A famous stable metal oxide, titanium(IV) oxide $\left(\mathrm{TiO}_{2}\right)$ was reported as a high photocatalyticperformance photocatalyst under ultraviolet (UV) light irradiation [5]. However, pristine $\mathrm{TiO}_{2}$ cannot absorb sunlight effectively due to large band gap energy of $3.2 \mathrm{eV}$ (absorb only $5 \%$ of sunlight). Therefore, visible light-active photocatalysts become more attractive for the solar photocatalysis.

In recent years, bismuth-based oxides were reported as visible lightactive photocatalysts owing to the interaction between $\mathrm{Bi}(6 \mathrm{~s})$ and $\mathrm{O}(2 \mathrm{p})$ making band-gap energy small corresponding to visible light region [6-8]. Monoclinic bismuth vanadate $\left(\mathrm{BiVO}_{4}\right.$, BVO) with narrow band gap energy of $2.4 \mathrm{eV}$ and high visible-light absorption is a good candidate and has been developed for more effective visible-light photocatalyst since there are some disadvantages such as slow charge transportation, rapid electron-hole recombination rate and photocorrosion [7-12]. Coupling BVO with appropriate band structure metal oxides (FeOOH/BVO [13], $\mathrm{TiO}_{2} / \mathrm{BVO}$ [14] and $\mathrm{BVO} / \mathrm{BiOCl}$ [15]) is an effective strategy to enhance photocatalytic activity and long-life reaction of the BVO. Similarly, bismuth tungstate $\left(\mathrm{Bi}_{2} \mathrm{WO}_{6}, \mathrm{BWO}\right)$ is another suitable support with a unique morphology and bandgap energy of $2.8 \mathrm{eV}$ [16]. It was reported that BWO had a good photocatalytic activity for oxygen liberation under visible light $(\lambda>420 \mathrm{~nm})$ and its photocatalytic activity was 
increased by increasing specific surface area and reducing lattice defect density $[16,17]$. Bismuth vanadate/bismuth tungstate $\left(\mathrm{BiVO}_{4} / \mathrm{Bi}_{2} \mathrm{WO}_{6}, \mathrm{BVO} / \mathrm{BWO}\right)$ heterojunction was firstly reported to show an improvement of decomposition of phenol under visible light over the individual components [18]. Furthermore, fraction of BVO content in composites $(f(\mathrm{~V}))$ played an important role in photocatalytic activity and the sample of $f(V)=1$ showed the best activity in photodegradation of methylene blue [19], photocatalytic degradation of Rhodamine B (RhB) [20] and photocatalytic antifouling activity [21]. Two-step process (hydrothermal and calcination) was applied to obtain uniform morphology and better crystallinity of the BVO/BWO composite leading to superior visible-light absorption and higher photodegradation activity for $\mathrm{RhB}$ [22]. Moreover, forming of BVO/BWO heterojunction facilitated electron-hole separation and charge transfer, which promoted photocatalytic activity [23,24].

Herein, we synthesized BVO/BWO composites in various $(f(\mathrm{~V}))$ and firstly report the results of photocatalytic oxygen liberation. The results of energy-resolved distribution of electron traps (ERDT) and conduction band-bottom (CBB) positions of BWO, BVO and $\mathrm{BVO} / \mathrm{BWO}$ composite were also for the first time analyzed and discussed. In addition, we found that BVO could be stabilized by loading on BWO and calcination at $873 \mathrm{~K}$ for $4 \mathrm{~h}$ was an important step to make better connection between BVO and BWO particles. In the case of calcination, photocatalytic activity was enhanced by adding BWO into the composite and it was depended on BVO fraction.

\section{Experimental}

\subsection{Sample preparation}

2.1.1. Synthesis of BVO

BVO was synthesized by using $1.0 \mathrm{mmol}$ bismuth(III) nitrate pentahydrate $\left(\mathrm{Bi}\left(\mathrm{NO}_{3}\right)_{3} \cdot 5 \mathrm{H}_{2} \mathrm{O}\right.$, 99.9\%, Wako Pure Chemical) dissolved in $2-\mathrm{mol} \mathrm{L}^{-1}$ nitric acid $(60 \%$, Wako Pure Chemical) and $1.0 \mathrm{mmol}$ ammonium metavanadate $\left(\mathrm{NH}_{4} \mathrm{VO}_{3}, 99.0 \%\right.$, Wako Pure Chemical) dissolved in 5-mol L ${ }^{-1}$ aqueous ammonia (25\%, Wako Pure Chemical) as starting materials. The vanadate solution was added dropwise to the bismuth solution and then the mixture was stirred. The $\mathrm{pH}$ of the mixture was adjusted to 7 by $2-\mathrm{mol} \mathrm{L}^{-1}$ nitric acid to obtain a bright yellow suspension. Then, $10 \mathrm{~mL}$ of ethanol (99.5\%; Wako Pure Chemical) was added to obtain a feed suspension. After stirred for $60 \mathrm{~min}$, the feed suspension was poured in a Teflon (PTFE) bottle with a stainless-steel outer bottle (San-ai Science HUT-100), heated at $473 \mathrm{~K}$ for $2 \mathrm{~h}$ in an oven and left to be cooled down to ambient temperature. The precipitate was collected by centrifugation at $3000 \mathrm{rpm}$, washed by Milli-Q water several times and dried at $393 \mathrm{~K}$ in an oven. The resultant yellow product, BVO, was calcined, if needed, at $873 \mathrm{~K}$ in air for $4 \mathrm{~h}$ (c-BVO).

\subsubsection{Synthesis of BVO/BWO composites}

Firstly, flake ball-shaped (FB) BWO particles were synthesized by hydrothermal reaction of an aqueous suspension containing bismuth (III) hydroxide and tungstic acid at 433 $\mathrm{K}$ for $20 \mathrm{~h}$ according to previous papers $[25,26]$. Then, BWO was added into a BVO feed suspension (see 2.1.1). The resultant suspension was vigorously stirred for $60 \mathrm{~min}$ and underwent hydrothermal reaction under the same conditions as those for the BVO preparation to obtain a BVO/BWO composite. Molar fraction of BVO $(f(\mathrm{~V}))$ was controlled by changing the ratio of the feed BVO and BWO to be 0.50 (BVO/BWO_0.50), 0.67 (BVO/BWO_0.67), 0.80 (BVO/BWO_0.80) or 0.91 (BVO/BWO_0.91). For calcined samples at $873 \mathrm{~K}$ in air for 4 h, "c-" was put before their names; e.g. 'c-BVO/BWO_0.50'. 


\subsection{Characterization of samples}

Surface morphologies of obtained powders were observed by a field emission scanning electron microscope (FE-SEM, JSM-7400F, JEOL) in secondary-electron image (SEI) mode and scanning transmission electron microscopy (STEM, HD2000 ultrathin film evaluation system, Hitachi). The FE-SEM was operated at $5.0 \mathrm{kV}$ electron-acceleration voltage, $10.0 \mu \mathrm{A}$ current and 5-6 mm working distance. Dried sample powder was placed onto a carbon tape (Okenshoji \#15-1096) stuck on a specimen stub (12 mm in diameter; $10 \mathrm{~mm}$ in height). In the case of STEM, sample powders were dispersed in methanol and sonicated in an ultrasound bath for a few seconds. Then suspension was dropped and dried on carbon covered cupper microgrid (NS-C15, Okenshoji). The images were observed using 3 mm working distance, $200 \mathrm{kV}$ accelerating voltage and $20 \mu \mathrm{A}$ emission current. Crystalline structures were analyzed by an X-ray diffractometer (XRD, SmartLab, Rigaku, Japan) with $\mathrm{Cu} \mathrm{K} \alpha$ radiation $(40 \mathrm{kV}, 30 \mathrm{~mA}, 0.154 \mathrm{~nm})$. XRD analysis was performed at a scanning rate of $1.0^{\circ} \mathrm{min}^{-1}$ and steps of $0.01^{\circ}$ in the $2 \theta$ range of $10-80^{\circ}$. Crystalline phases of BVO and BWO were compared with Joint Committee on Powder Diffraction Standards (JCPDS) file No.14-0688 and 79-2381, respectively. Primary particle size (or crystallite size) was evaluated by a corrected width of the most intensive XRD peak of each crystalline phase (121) for BVO and (131) for BWO using Scherrer equation [27, 28]. Band gap energy was calculated by Kubelka-Munk (K-M) function analyzed by UV-vis diffuse reflectance spectrometer (UV-vis DRS, V670, Jasco). Barium sulfate was used as a white reflectance standard. Specific surface area (SSA) was estimated based on nitrogen adsorption measurement at $77 \mathrm{~K}$ (NOVA 1200e surface-area and pore-size analyzer, Quantachrome (previously Yuasa Ionics)) and calculated by Brunauer-Emmett-Teller (BET) method. A sample powder was pre-heated under nitrogen atmosphere at $423 \mathrm{~K}$ for $90 \mathrm{~min}$ before analysis. ERDT and CBB positions were measured by reversed double-beam photoacoustic spectroscopy (RDB-PAS) and single-beam PAS, respectively, using laboratory-made RDBPAS apparatus [29].

\subsection{Photocatalytic activity test}

Photocatalytic activities of the samples were evaluated by the rate of oxygen liberation. A photocatalyst (50 mg) was suspended in an aqueous solution of iron(III) chloride (5.0 mL; $0.25 \mathrm{mmol}$ ) in a glass tube. After sonicated for $15 \mathrm{~min}$, argon bubbling was applied for 15 min to purge off air and the suspension was photoirradiated by UV-vis light (a 400-W high-pressure mercury arc) or visible-light (a 300-W xenon arc with a Y44 cut-off glass filter (Hoya, Japan) transmitting light of wavelength>ca. $420 \mathrm{~nm}$ ) in a thermostatic bath (298 K). The amount of liberated oxygen in the gas phase of a glass tube was measured by a TCD-gas chromatograph (GC, GC-8A, Shimadzu, Japan) with a molecular sieve 5A column to calculate the rate of oxygen liberation. Since contamination of air could not be thoroughly excluded, the amount of evolved oxygen was calibrated with the amount of nitrogen measured by the chromatograms on the assumption that air, as a mixture of nitrogen and oxygen, was contaminated in the samples tubes and the molar amount of corresponding contaminated oxygen can be calculated by that of nitrogen. Reusability of BVO, BVO/BWO_0.80, c-BVO and c-BVO/BWO_0.80 photocatalysts was tested in the same condition under visible light for 5 cycles. After the visible-light irradiation for $30 \mathrm{~min}$ in every cycle, generated oxygen gas was removed by argon-gas bubbling for $15 \mathrm{~min}$. The next cycle was started under visible-light irradiation and $0.20 \mathrm{~mL}$ of gas was sampled every 10 min until reached $30 \mathrm{~min}$. Amount of produced oxygen was analyzed by TCD-GC. 


\section{Results and discussion}

\subsection{Morphologies of BVO, BWO and BVO/BWO composites}

The morphology of synthesized BVO was small rod-like particles of ca. $100 \mathrm{~nm}$ in width and ca. $200 \mathrm{~nm}$ in length as shown in Fig. 1(a), and they were agglomerated and densified by calcination to produce larger particles with grain boundaries (Fig. 1(b)).

(Fig. 1. FE-SEM images of (a) BVO, (b) c-BVO, (c) BWO, (d) c-BWO, (e)-(h) BVO/BWO composites and (i)-(l) c-BVO/BWO composites with $f(V)=0.50,0.67$,

$$
0.80 \text { and } 0.91 \text {, respectively.) }
$$

In addition, hydrothermally synthesized FB-BWO was analyzed by SEM images as shown in Fig. 1(c). All the BWO particles were assemblies of flakes with their outer diameter of ca. 5 $\mu \mathrm{m}$ as has been reported previously [26]. The particle size was decreased by ca. $10-20 \%$ by calcination at $873 \mathrm{~K}$ for $4 \mathrm{~h}$ (Fig. 1(d)) presumably due to shrinkage and fusion of flakes. On the other hand, BVO/BWO showed different results when calcined. Figs. 1(e)-(h) show morphologies of $\mathrm{BVO} / \mathrm{BWO}$ with $f(\mathrm{~V})$ of $0.50,0.67,0.80$ and 0.91 , respectively, before calcination. As expected based on the preparation process, it seems that small BVO particles were partially deposited on and between flakes in FB-BWO particles. It was also noticed that when $f(\mathrm{~V})$ was increased, morphologies of the composites were similar, however, BVO/BWO_0.80 particle was much more covered by rod-like BVO particles than other composites. Moreover, from the surface observation of the BVO/BWO_0.80 particles by STEM, it was confirmed that rod particles were deposited on BWO flakes as shown in Fig. 2(a).

(Fig. 2. STEM images of (a) BVO/BWO_0.80 and (b) c-BVO/BWO_0.80

$$
\text { composites.) }
$$

On the other hand, by the 873-K calcination (Fig. 1(i)-(l)), the deposited small BVO particles were interconnected and grown larger. The same phenomenon could also be observed by STEM as shown in Fig. 2(b). The surface of c-BVO/BWO_0.80 composite was composed of BVO with smooth surface and various particles sizes, but not formed by large sintered particles as seen for c-BVO in Fig. 1(b). In other word, BVO particles were stabilized on FBBWO particles against heat-induced sintering.

\subsection{Crystalline structures of BVO, BWO and BVO/BWO composites}

Crystalline phase structures of all samples were analyzed by XRD and shown in Fig. 3.

(Fig. 3. X-ray diffraction patterns of (A) uncalcined and (B) calcined (a) BWO, (b)-(e) $\mathrm{BVO} / \mathrm{BWO}$ composites with $\mathrm{f}(\mathrm{V})=0.50,0.67,0.80$ and 0.91 , respectively, and (f)

\section{BVO.)}

XRD patterns of BWO (Fig. 3A(a)) and BVO (Fig. 3A(f)) were defined as orthorhombic and monoclinic structure, respectively, without any impurity peaks. Consequently, BVO/BWO composites were composed of monoclinic phase of BVO and orthorhombic phase of BWO, peak intensities of which were related to BVO/BWO mole ratio as shown in Fig. 3A(b)-(e). Crystalline phases did not change even after calcination at $873 \mathrm{~K}$ for $4 \mathrm{~h}$ as showed in Fig. 3B. Diffraction patterns of calcined composites remained in the combination of the monoclinic and orthorhombic structures. However, marked increase in the peak intensities indicated an improvement of the crystallinities of all samples and increase in the crystalline 
sizes indicated crystalline growth by calcination. All characteristics of the samples synthesized in this work were summarized in Table 1.

(Table 1 Physical properties and photocatalytic activities of uncalcined and calcined BWO, BVO and BVO/BWO composites under UV-vis and visible light.)

\subsection{Photoabsorption properties of BVO, BWO and BVO/BWO composites}

Fig. 4 shows diffuse reflectance spectra of uncalcined (Fig. 4A) and calcined (Fig. 4B) samples.

(Fig. 4. UV-vis DRS spectra of (A) uncalcined and (B) calcined (a) BWO, (b)-(e)

$\mathrm{BVO} / \mathrm{BWO}$ composites with $\mathrm{f}(\mathrm{V})=0.50,0.67,0.80$ and 0.91 , respectively, and (f)

$$
\text { BVO.) }
$$

It was found that all samples exhibited strong absorption in UV and visible region. The absorption edges of BVO and BVO/BWO composites were shown at approximately $530 \mathrm{~nm}$ while BWO had shorter edge at $450 \mathrm{~nm}$. In addition, the edge positions for c-BWO and cBVO/BWO were slightly shifted comparing to BWO and BVO/BWO, respectively, on the other hand, that of c-BVO was greatly shifted to a longer wavelength at $550 \mathrm{~nm}$. In order to evaluate photoabsorption property of a semiconductor, band gap energy (Eg) was calculated by the following equation:

$$
\mathrm{F}(\mathrm{R}) \mathrm{E}=\mathrm{A}(\mathrm{E}-\mathrm{Eg})^{\mathrm{n}}
$$

where $\mathrm{A}$ is a constant, $\mathrm{E}$ is the photon energy $(\mathrm{eV}) ; \mathrm{E}=1240 / \lambda$ ( $\lambda=$ =wavelength in $\mathrm{nm}$ unit), $n=1 / 2$ (in the case of $B V O$ ) and 2 (in the case of $B W O$ ), and $F(R)$ is a function of reflectance. The band gap energies of BVO and BWO were 2.64 and $3.04 \mathrm{eV}$, respectively, and those of composites were similar to that of BVO. In addition, they were reduced by calcination for all the samples, but not significantly affected by varying $f(V)$. As shown in Table 1 , c-BVO and $\mathrm{c}-\mathrm{BVO} / \mathrm{BWO}$ were promised to be the most visible light-active photocatalysts due to narrow band-gap energies.

\subsection{Surface structure of BVO, BWO and BVO/BWO composites}

Fig. 5 shows ERDT and CBB position of samples plotted as a function of energy (eV) from the top of valence band (VBT) of each sample.

(Fig. 5. ERDT patterns of BWO, c-BWO, BVO, c-BVO, BVO/BWO and c-

BVO/BWO. Numbers in $<>$ denote the total density of ETs in the unit of $\mu \mathrm{mol} \mathrm{g}{ }^{-1}$.

The last row is specific surface area in the unit of $\mathrm{m}^{2} \mathrm{~g}^{-1}$.)

As has been reported previously [29], metal-oxide powders may have electron traps (ETs), localized electronic states accepting electrons, with their energies close to CBB, and those ETs are presumed to be located mainly on the surface of powders, i.e., ERDT reflects the surface structure of metal-oxide powders. For the samples used in the present study, ERDT/CBB patterns were observed similar to the other metal oxides. Being consistent with the results of band gaps measured by DRS as described above, apparent CBB, showing band gap energy with reference to VBT, of BWO was higher than that of BVO. The same as the other metal oxide particles, parts of ETs were located in the energy range close to or slightly above CBB for all samples (The reasons for the presence of ETs in the conduction band has been discussed in the previous paper [29]). 
Comparing ERDT patterns of BWO, BVO and BVO/BWO, the BVO/BWO pattern was found to be reproduced by summations of the ERDT patterns of BVO and BWO with ca. $0.4 \mathrm{eV}$ anodic (downward) shift of the BWO pattern, on the assumption that ETs in BVO and BWO gave ERDT patterns independently. This suggests that apparent VBT of BWO is more anodic by ca. $0.4 \mathrm{eV}$ than that of BVO and, as a result, apparent CBB of BVO and BWO are almost the same position, being consistent with previous reports [7,18,22,30]. Anyway, the fact that the ERDT pattern of composites could be reproduced only by summation of those of each component suggests negligible electron/positive hole transfer between two components [31], which have been often presumed for the other composite photocatalysts [32,33].

\subsection{Photocatalytic activities}

Figs. 6.1 and 6.2 show photocatalytic activities of BWO, BVO, BVO/BWO and their calcined samples in various $f(\mathrm{~V})$ under $\mathrm{UV}$-vis and visible-light irradiation, respectively.

(Fig. 6. 1 Photocatalytic oxygen liberations under UV-vis light using (A) uncalcined and (B) calcined BWO, BVO and BVO/BWO composites. 2 Photocatalytic oxygen liberations under visible light using (A) uncalcined and (B) calcined BWO, BVO and BVO/BWO composites.)

At the beginning of photocatalysis under UV-vis light irradiation (Fig. 6.1A), BVO and BWO showed the highest and lowest-level photocatalytic rate, 14 and $2 \mu \mathrm{mol} \mathrm{h} \mathrm{h}^{-1}$, respectively. However, the activity of BVO was dropped down and became to be lower than that of BVO/BWO_0.91 after 1-h irradiation. Thus, BVO/BWO_0.91 sample exhibited the highest activity for prolonged reaction time to $1.5 \mathrm{~h}$. In contrast, activity of c-BVO was lower than calcined composites and much decreased when compared to BVO (Fig. 6.1B). The highest activity among the calcined samples was observed for c-BVO/BWO_0.91. In the case of photocatalytic activities under visible-light irradiation, the similar results as in the case under

UV-vis irradiation were obtained, but c-BVO/BWO_0.80 showed the highest activity among the calcined samples (Fig. 6.2B), while BVO still kept higher activity after 1.5-h visible-light irradiation (Fig. 6.2A). It seems strange, in the ordinary sense in the field of photocatalysis studies, that the c-BVO/BWO activities were almost the same degree as those of BVO/BWO though the SSA was a few times decreased by the calcination. However, as has been reported previously [34], photocatalytic activities of commercial titania samples for oxygen evolution in the presence of electron acceptors, but not ordinary organics decomposition reactions, were predominantly regulated by their secondary particle size (SPS) and the larger the SPS of the samples were, the higher their photocatalytic activities became. This may be because the larger particle size is required to absorb multiple photons within the life time of an electronpositive hole pair to drive oxygen evolution with four-electron transfer process. The observed activity not so decreased by calcination of BVO/BWO composites $(f(\mathrm{~V})<0.8)$ could be explained by the stabilization of loaded small BVO particles, not to be aggregated but keeping the high dispersion of BVO particles.

Fig. 7 shows rates of photocatalytic activities after 30 -min light irradiation as a function of BVO content in composites, $f(\mathrm{~V})$.

(Fig. 7. Photocatalytic activities of BVO/BWO and c-BVO/BWO composites as a

function of $f(\mathrm{~V})$. Open and closed circles: uncalcined and calcined samples, respectively, under UV-vis irradiation. Open and closed triangles: uncalcined and calcined samples, respectively, under visible-light irradiation.) 
Photocatalytic activities were obviously increased with increasing $f(V)$ for the uncalcined samples under both UV-vis and visible-light irradiations. For the calcined samples, on the other hand, the activities increased with increasing $f(\mathrm{~V})$ to attain the maximum at $f(\mathrm{~V})=0.8$ and then decreased to result in the relatively lower activity of c-BVO. In other words, both UV-vis and visible-light activities of BVO were largely decreased to be ca. $30 \%$ by calcination (c-BVO), while the activity of BVO/BWO composites, owing predominantly to vanadate component (Note the relatively lower activity of BWO and almost linearly increasing BVO activity with $f(\mathrm{~V})$ ), was kept almost the same degree (or slightly decreased) even after calcination. It could be said that the photochemical reaction occurred mainly on BVO particles and tungsten components were negligibly active, but they helped to stabilize the BVO particles when they were calcined. In this sense, uncalcined pristine BVO was the best photocatalyst, but as shown in Fig. 8 and discussed in the following section, the stability of uncalcined BVO was worse than those of calcined samples.

The above-mentioned photocatalytic-activity trends can reasonably be interpreted by the change in morphology by calcination. As shown in Figs. 1 and 2, relatively smaller-sized BVO was fused and sintered to become larger-sized particles possibly creating grain boundaries, while such larger-sized BVO particles were not formed on BWO particles by calcination. Furthermore, the morphological change of the BVO particles could reflect ERDT/CBB patterns shown in Fig. 5. The total ET density of BVO $\left(34 \mu \mathrm{mol} \mathrm{g}{ }^{-1}\right)$ was reduced almost by half by calcination (16 $\mu \mathrm{mol} \mathrm{g}$ ), though SSA was reduced to be less than $10 \%$ (Table 1). Taking into consideration that the partial density of shallower ETs located around CBB seemed to become less than half by calcination, the above-mentioned change in total ET density suggests that deeper ETs might be increased by calcination presumably due to crystalline defects at the grain boundaries of c-BVO, as was claimed in a previous research [35]. Analysis of ERDT patterns of composites with various $f(V)$ and a correlation between photocatalytic activities and ERDT/CBB patterns is another valuable target and further studies along this line as well as a study on calculating absolute position of ERDT/CBB are now underway.

\subsection{Sedimentation of BVO and BVO/BWO composites}

Although BVO was the most active photocatalyst for oxygen liberation among the samples used in this study, c-BVO/BWO with a large overall particle size has potential for separating photocatalyst from the reaction mixture after photoirradiation. Sedimentation test (Fig. 8) showed that BVO photocatalysts were still stably dispersed in water, on the other hand, the supernatant of a c-BVO/BWO_0.80 suspension was clear after 78-h standing.

(Fig. 8. Sedimentation of (a) BVO and (b) c-BVO/BWO_0.80.)

This is one of the advantages of c-BVO/BWO_0.80 for practical applications in the future.

\subsection{Reusability}

Long-life photocatalyst is an important property for practical applications. Reusability of c-BVO/BWO_0.80 composite was tested and compared to BVO, c-BVO and BVO/BWO_0.80 as showed in Fig. 9.

(Fig. 9. Reusability of BVO, c-BVO, BVO/BWO_0.80 and c-BVO/BWO_0.80

$$
\text { composites.) }
$$

In the first cycle, BVO showed the highest activity, however, rapid decreases in photocatalytic activity were presented in the second cycle for all the samples. After 2.5-h irradiation, the activities of BVO, c-BVO, BVO/BWO_0.80 and c-BVO/BWO_0.80 were 
reduced to $16 \%, 24 \%, 25 \%$ and $45 \%$ of the first cycle, respectively. It was illustrated that the c-BVO/BWO composite was more stable under visible-light irradiation than the others.

\section{Conclusion}

On the basis of above-mentioned results and discussion, it is concluded that BVO and BWO components exhibit photocatalytic activity independently, i.e., without possible electron/positive hole transfer between two kinds of metal oxides since the photocatalytic activity for oxygen liberation changed linearly with changing BVO contents in uncalcined $\mathrm{BVO} / \mathrm{BWO}$ composites. Another support for the independence of two components is that ERDT of the uncalcined composite can be reproduced by summation of the ERDT patterns of each component by assuming that VBT of BWO is lower (more anodic) by ca. $0.4 \mathrm{eV}$ than that of BVO; if electron or positive-hole transfer happens between two components, the ERDT pattern of composites might not be a simple summation. The fact that the calcined composites showed the maximum photocatalytic activity at the BVO composition of $80 \%$ is attributable to the ability of BWO to keep the BVO activity after calcination by preventing the aggregation and fusion of the BVO crystallites into large, less active, particles. In general, relatively higher photocatalytic activity of composite materials compared to those of single components, often called "synergetic effect", has been attributed to the interparticle electron/positive-hole transfers without showing the experimental evidence for the charge transfer. For the c-BVO/BWO composite photocatalysts reported in this paper, the maximum activity was observed due to physically stabilized BVO particles by BWO in calcination rather than to possible charge transfer between two components. Thus, synergetic effects are not always owing to electronic effect, but, at least in the present case, to morphological effect or the others, and this must be important to design composite materials with high-level photocatalytic activity.

\section{Acknowledgement}

This work was financially supported by the Research Professional Development Project Under the Science Achievement Scholarship of Thailand (SAST). The analyses of photocatalyst particles were carried out using FE-SEM and STEM at the OPEN FACILITY, Hokkaido University Sousei Hall. We would also particularly like to thank Ms. Haruna Hori and Ms. Maya Endo for their valuable technical assistance and helpful suggestions. 


\section{References}

[1] D. Ke, T. Peng, L. Ma, P. Cai, K. Dai, Effects of hydrothermal temperature on the microstructures of $\mathrm{BiVO}_{4}$ and its photocatalytic $\mathrm{O}_{2}$ evolution activity under visible light, Inorg. Chem. 48 (2009) 4685-4691.

[2] Z. Zhang, W. Wang, M. Shang, W. Yin, Photocatalytic degradation of rhodamine B and phenol by solution combustion synthesized $\mathrm{BiVO}_{4}$ photocatalyst, Catal. Commun. 11 (2010) 982-986.

[3] D. Spasiano, R. Marotta, S. Malato, P. Fernandez-Ibañez, I. Di Somma, Solar photocatalysis: materials reactors, some commercial, and pre-industrialized applications. A comprehensive approach, Appl. Catal. B: Environ. 170 (2015) 90-123.

[4] T. Hisatomi, J. Kubota, K. Domen, Recent advances in semiconductors for photocatalytic and photoelectrochemical water splitting, Chem. Soc. Rev. 43 (2014) 7520-7535.

[5] A. Fujishima, T.N. Rao, D.A. Tryk, Titanium dioxide photocatalysis, J. Photochem. Photobiol. C: Photochem. Rev. 1 (2000) 1-21.

[6] T. Saison, N. Chemin, C. Chanéac, O. Durupthy, V. Ruaux, L. Mariey, F. Maugé, P. Beaunier, J.-P. Jolivet, $\mathrm{Bi}_{2} \mathrm{O}_{3}, \mathrm{BiVO}_{4}$, and $\mathrm{Bi}_{2} \mathrm{WO}_{6}$ : impact of surface properties on photocatalytic activity under visible light, J. Phys. Chem. C 115 (2011) 5657-5666.

[7] D. Kang, Y. Park, J.C. Hill, K.-S. Choi, Preparation of Bi-based ternary oxide photoanodes $\mathrm{BiVO}_{4}, \mathrm{Bi}_{2} \mathrm{WO}_{6}$, and $\mathrm{Bi}_{2} \mathrm{Mo}_{3} \mathrm{O}_{12}$ using dendritic $\mathrm{Bi}$ metal electrodes, J. Phys. Chem. Lett. 5 (2014) 2994-2999.

[8] J.K. Cooper, S. Gul, F.M. Toma, L. Chen, P.-A. Glans, J. Guo, J.W. Ager, J. Yano, I.D. Sharp, Electronic structure of monoclinic $\mathrm{BiVO}_{4}$, Chem. Mater. 26 (2014) 5365-5373.

[9] A. Kudo, K. Omori, H. Kato, A novel aqueous process for preparation of crystal formcontrolled and highly crystalline $\mathrm{BiVO}_{4}$ powder from layered vanadates at room temperature and its photocatalytic and photophysical properties, J. Am. Chem. Soc. 121 (1999) 1145911467.

[10] J. Su, L. Guo, N. Bao, C.A. Grimes, Nanostructured $\mathrm{WO}_{3} / \mathrm{BiVO}_{4}$ heterojunction films for efficient photoelectrochemical water splitting, Nano Lett. 11 (2011) 1928-1933.

[11] M. Yao, M. Liu, L. Gan, F. Zhao, X. Fan, D. Zhu, Z. Xu, Z. Hao, L. Chen, Monoclinic mesoporous $\mathrm{BiVO}_{4}$ : synthesis and visible-light-driven photocatalytic property, Colloids Surf. A Physicochem. Eng. Asp. 433 (2013) 132-138.

[12] T.S. Sinclair, B.M. Hunter, J.R. Winkler, H.B. Gray, A.M. Muller, Factors affecting bismuth vanadate photoelectrochemical performance, Mater. Horiz. 2 (2015) 330-337. [13] J.A. Seabold, K.-S. Choi, Efficient and stable photo-oxidation of water by a bismuth vanadate photoanode coupled with an iron oxyhydroxide oxygen evolution catalyst, J. Am. Chem. Soc. 134 (2012) 2186-2192.

[14] M. Xie, X. Fu, L. Jing, P. Luan, Y. Feng, H. Fu, Long-lived, visible-light-excited charge carriers of $\mathrm{TiO}_{2} / \mathrm{BiVO}_{4}$ nanocomposites and their unexpected photoactivity for water splitting, Adv. Energy Mater. 4 (2014) 1300995.

[15] D. Lv, D. Zhang, X. Pu, D. Kong, Z. Lu, X. Shao, H. Ma, J. Dou, One-pot combustion synthesis of $\mathrm{BiVO}_{4} / \mathrm{BiOCl}$ composites with enhanced visible-light photocatalytic properties, Sep. Purif. Technol. 174 (2017) 97-103.

[16] F. Amano, K. Nogami, R. Abe, B. Ohtani, Preparation and characterization of bismuth tungstate polycrystalline flake-ball particles for photocatalytic reactions, J. Phys. Chem. C 112 (2008) 9320-9326.

[17] A. Kudo, S. Hijii, $\mathrm{H}_{2}$ or $\mathrm{O}_{2}$ evolution from aqueous solutions on layered oxide photocatalysts consisting of $\mathrm{Bi}^{3+}$ with $6 \mathrm{~s}^{2}$ configuration and $\mathrm{d}^{\circ}$ transition metal ions, Chem. Lett. 28 (1999) 1103-1104. 
[18] X. Zhang, Y. Gong, X. Dong, X. Zhang, C. Ma, F. Shi, Fabrication and efficient visible light-induced photocatalytic activity of $\mathrm{Bi}_{2} \mathrm{WO}_{6} / \mathrm{BiVO}_{4}$ heterojunction, Mater. Chem. Phys. 136 (2012) 472-476.

[19] S. Chaiwichian, B. Inceesungvorn, K. Wetchakun, S. Phanichphant, W.

Kangwansupamonkon, N. Wetchakun, Highly efficient visible-light-induced photocatalytic activity of $\mathrm{Bi}_{2} \mathrm{WO}_{6} / \mathrm{BiVO}_{4}$ heterojunction photocatalysts, Mater. Res. Bull. 54 (2014) 28-33. [20] S. Xue, Z. Wei, X. Hou, W. Xie, S. Li, X. Shang, D. He, Enhanced visible-light photocatalytic activities and mechanism insight of $\mathrm{BiVO}_{4} / \mathrm{Bi}_{2} \mathrm{WO}_{6}$ composites with viruslike structures, Appl. Surf. Sci. 355 (2015) 1107-1115.

[21] P. Ju, Y. Wang, Y. Sun, D. Zhang, Controllable one-pot synthesis of a nest-like $\mathrm{Bi}_{2} \mathrm{WO}_{6} / \mathrm{BiVO}_{4}$ composite with enhanced photocatalytic antifouling performance under visible light irradiation, Dalton Trans. 45 (2016) 4588-4602.

[22] P. Ju, P. Wang, B. Li, H. Fan, S. Ai, D. Zhang, Y. Wang, A novel calcined $\mathrm{Bi}_{2} \mathrm{WO}_{6} / \mathrm{BiVO}_{4}$ heterojunction photocatalyst with highly enhanced photocatalytic activity, Chem. Eng. J. 236 (2014) 430-437.

[23] H. Fan, D. Wang, Z. Liu, T. Xie, Y. Lin, Self-assembled $\mathrm{BiVO}_{4} / \mathrm{Bi}_{2} \mathrm{WO}_{6}$ microspheres: synthesis, photoinduced charge transfer properties and photocatalytic activities, Dalton Trans. 44 (2015) 11725-11731.

[24] L. Chen, D. Meng, X. Wu, A. Wang, J. Wang, M. Yu, Y. Liang, Enhanced visible light photocatalytic performances of self-assembled hierarchically structured $\mathrm{BiVO}_{4} / \mathrm{Bi}_{2} \mathrm{WO}_{6}$ heterojunction composites with different morphologies, RSC Adv. 6 (2016) 52300-52309. [25] H. Hori, M. Takase, F. Amano, B. Ohtani, Mechanism of the formation of hierarchicalstructured bismuth tungstate photocatalyst particles through counter-flow supply of bismuth and tungsten sources, Chem. Lett. 44 (2015) 1723-1725.

[26] H. Hori, M. Takase, M. Takashima, F. Amano, T. Shibayama, B. Ohtani, Mechanism of formation, structural characteristics and photocatalytic activities of hierarchicalstructured bismuth-tungstate particles, Catal. Today 300 (2018) 99-111.

[27] B. Ohtani, Preparing articles on photocatalysis - beyond the illusions misconceptions, and speculation, Chem. Lett. 37 (2008) 216-229.

[28] A.K. Bhattacharya, K.K. Mallick, A. Hartridge, Phase transition in $\mathrm{BiVO}_{4}$, Mater. Lett. 30 (1997) 7-13.

[29] A. Nitta, M. Takase, M. Takashima, N. Murakami, B. Ohtani, A fingerprint of metaloxide powders: energy-resolved distribution of electron traps, Chem. Commun. 52 (2016) 12096-12099.

[30] J. Zhang, T. Wang, X. Chang, A. Li, J. Gong, Fabrication of porous nanoflake BiMO $(\mathrm{M}=\mathrm{W}, \mathrm{V}$, and $\mathrm{Mo}$ ) photoanodes via hydrothermal anion exchange, Chem. Sci. 7 (2016) 6381-6386.

[31] B. Ohtani, O.O. Prieto-Mahaney, D. Li, R. Abe, What is Degussa (Evonik) P25? Crystalline composition analysis, reconstruction from isolated pure particles and photocatalytic activity test, J. Photochem. Photobiol. A: Chem. 216 (2010) 179-182.

[32] X. Lin, F. Huang, J. Xing, W. Wang, F. Xu, Heterojunction semiconductor $\mathrm{SnO}_{2} / \mathrm{SrNb}_{2} \mathrm{O}_{6}$ with an enhanced photocatalytic activity: the significance of chemically bonded interface, Acta Mater. 56 (2008) 2699-2705.

[33] Q. Jia, A. Iwase, A. Kudo, $\mathrm{BiVO}_{4}-\mathrm{Ru} / \mathrm{SrTiO}_{3}$ : Rh composite Z-scheme photocatalyst for solar water splitting, Chem. Sci. 5 (2014) 1513-1519.

[34] B. Ohtani, O.-O. Prieto-Mahaney, F. Amano, N. Murakami, R. Abe, What are titania photocatalysts?-An exploratory correlation of photocatalytic activity with structural and physical properties, J. Adv. Oxid. Technol. 13 (2010) 247-261.

[35] J. Yu, A. Kudo, Effects of structural variation on the photocatalytic performance of hydrothermally synthesized $\mathrm{BiVO}_{4}$, Adv. Funct. Mater. 16 (2006) 2163-2169. 
Table 1 Physical properties and photocatalytic activities of uncalcined and calcined BWO, BVO and BVO/BWO composites under UV-vis and visible light.

\begin{tabular}{|c|c|c|c|c|c|c|c|c|c|c|c|c|c|c|c|}
\hline \multirow{3}{*}{ Samples } & \multirow{3}{*}{$f(\mathrm{~V})$} & \multicolumn{7}{|c|}{ Uncalcined } & \multicolumn{7}{|c|}{ Calcined } \\
\hline & & \multirow{2}{*}{$\begin{array}{c}D^{a} \\
/ \mathrm{nm}\end{array}$} & \multirow{2}{*}{$\begin{array}{c}E_{\mathrm{g}} \\
/ \mathrm{eV}\end{array}$} & \multirow{2}{*}{$\begin{array}{l}\mathrm{SSA}^{\mathrm{b}} \\
/ \mathrm{m}^{2} \mathrm{~g}^{-1}\end{array}$} & \multicolumn{2}{|c|}{ UV-visible } & \multicolumn{2}{|c|}{ visible } & \multirow{2}{*}{$\begin{array}{c}D^{a} \\
/ \mathrm{nm}\end{array}$} & \multirow{2}{*}{$\begin{array}{c}E_{\mathrm{g}} \\
/ \mathrm{eV}\end{array}$} & \multirow{2}{*}{$\begin{array}{l}\mathrm{SSA}^{\mathrm{b}} \\
/ \mathrm{m}^{2} \mathrm{~g}^{-1}\end{array}$} & \multicolumn{2}{|c|}{ UV-visible } & \multicolumn{2}{|c|}{ visible } \\
\hline & & & & & $\begin{array}{c}\text { Rate } \\
/ \mu \mathrm{mol} \mathrm{h}{ }^{-1}\end{array}$ & $R^{2}$ & $\begin{array}{c}\text { Rate } \\
/ \mu \mathrm{mol} \mathrm{h}{ }^{-1}\end{array}$ & $R^{2}$ & & & & $\begin{array}{c}\text { Rate } \\
/ \mu \mathrm{mol} \mathrm{h}{ }^{-1}\end{array}$ & $R^{2}$ & $\begin{array}{c}\text { Rate } \\
/ \mu \mathrm{mol} \mathrm{h}{ }^{-1}\end{array}$ & $R^{2}$ \\
\hline \multirow[t]{3}{*}{ BWO } & 0 & 16 & 3.04 & 19 & 1.91 & 0.9825 & 0.38 & 0.9440 & 29 & 2.87 & 4 & 2.71 & 0.9943 & 0.15 & 0.9523 \\
\hline & 0.50 & 31 & 2.66 & NA & 8.64 & 0.9898 & 2.04 & 0.9734 & 47 & 2.55 & NA & 6.20 & 0.9908 & 1.84 & 0.9759 \\
\hline & 0.67 & 26 & 2.64 & NA & 10.45 & 0.9952 & 5.08 & 0.9525 & 60 & 2.58 & NA & 7.79 & 0.9880 & 3.80 & 0.9847 \\
\hline \multirow{2}{*}{ BVO/BWO } & 0.80 & 29 & 2.64 & 14 & 11.33 & 0.9932 & 4.82 & 0.9820 & 56 & 2.57 & 3 & 9.44 & 0.9909 & 4.10 & 0.9859 \\
\hline & 0.91 & 36 & 2.63 & NA & 12.77 & 0.9929 & 6.73 & 0.9790 & 58 & 2.58 & NA & 8.64 & 0.9865 & 3.60 & 0.9940 \\
\hline BVO & 1 & 42 & 2.64 & 12 & 14.01 & 0.9932 & 7.90 & 0.9910 & 62 & 2.54 & 1 & 4.62 & 0.9912 & 1.90 & 0.9824 \\
\hline
\end{tabular}

N/A = Not analyzed

${ }^{\text {a }}$ Crystalline sizes (D) of BWO and BVO were calculated by (131) and (121) XRD peaks, respectively.

${ }^{\mathrm{b}}$ Specific surface area 
Flake-ball structure of BWO prohibits the growth of loaded BVO by separating them to result in $\mathrm{BVO}$ with higher stability

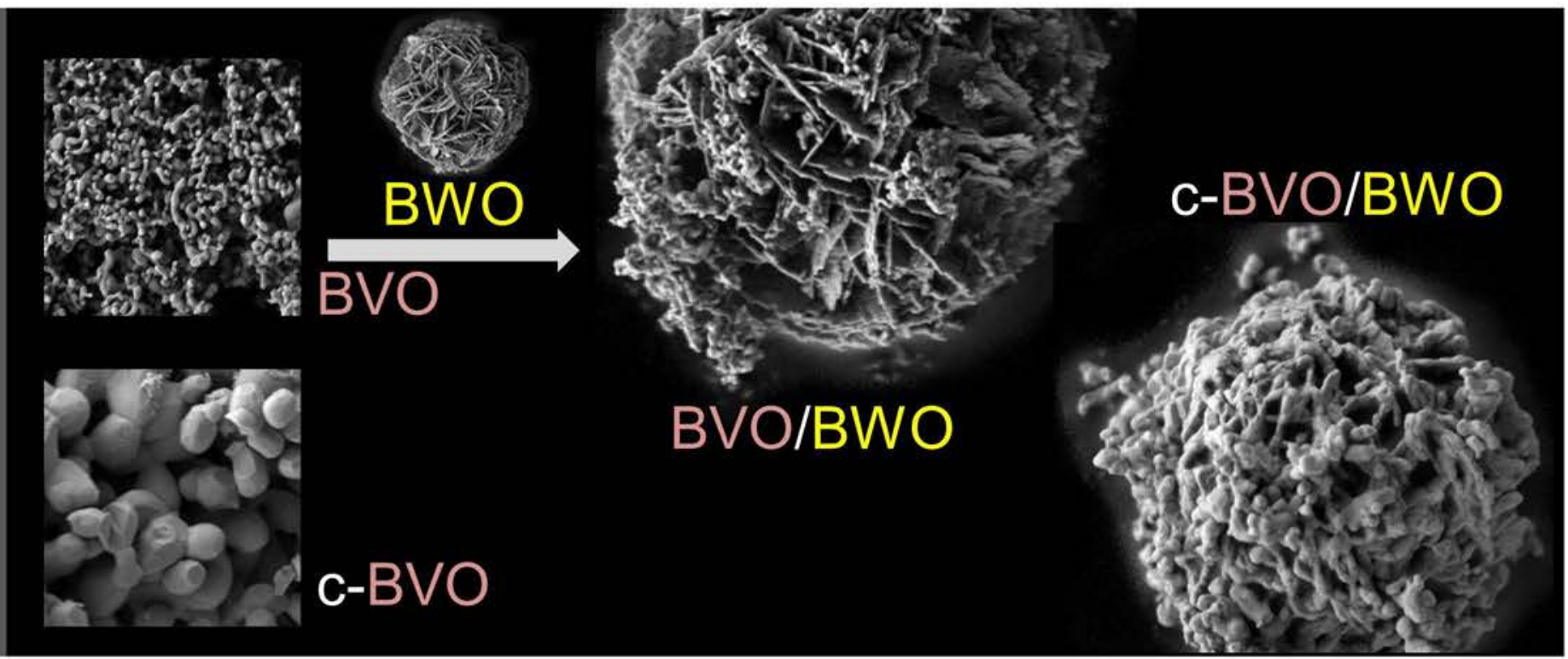

Graphic abstract 



Fig. 1 

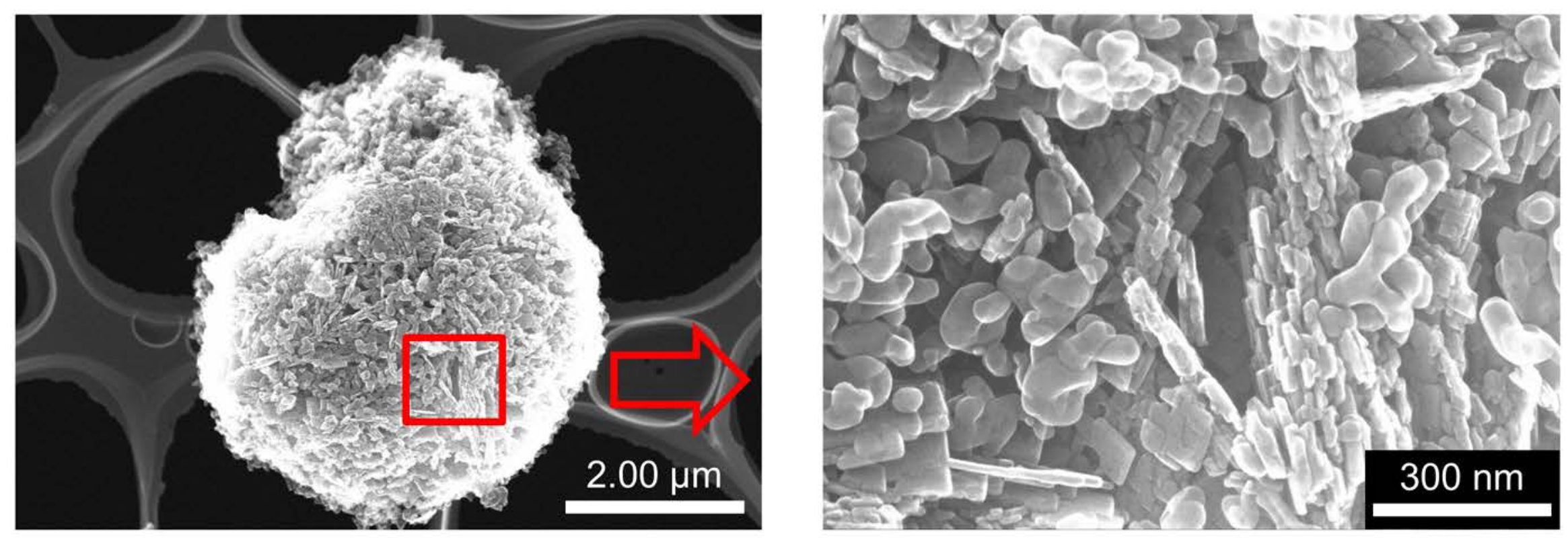

(a)
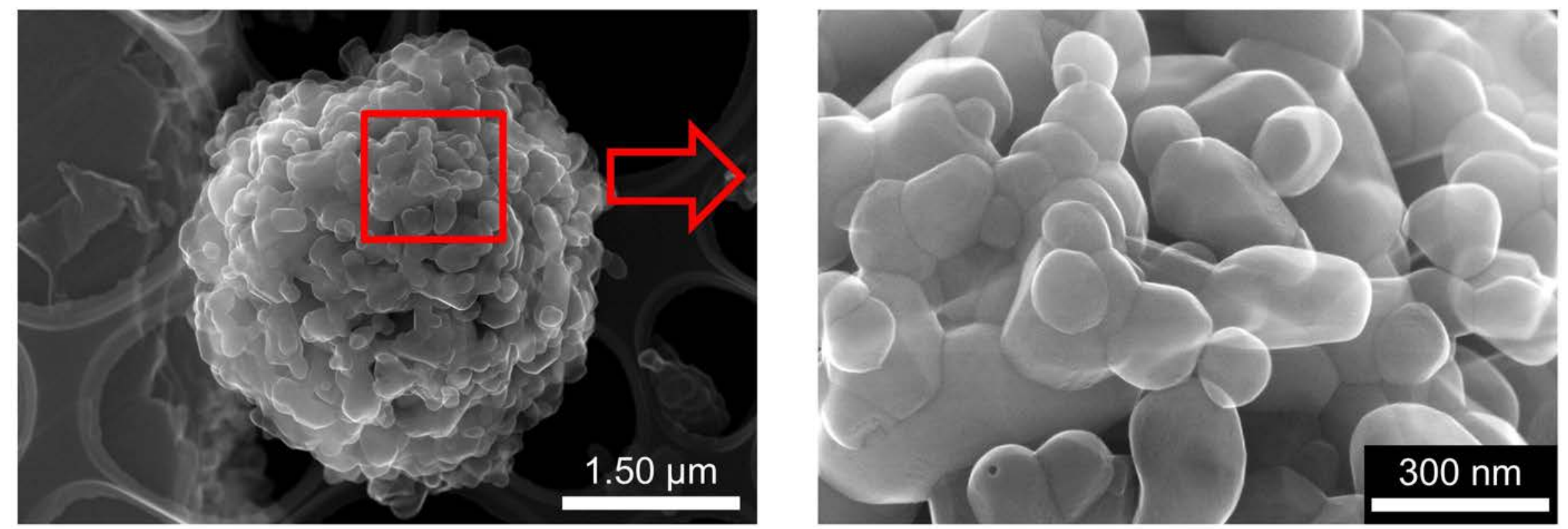

Fig. 2

(b) 


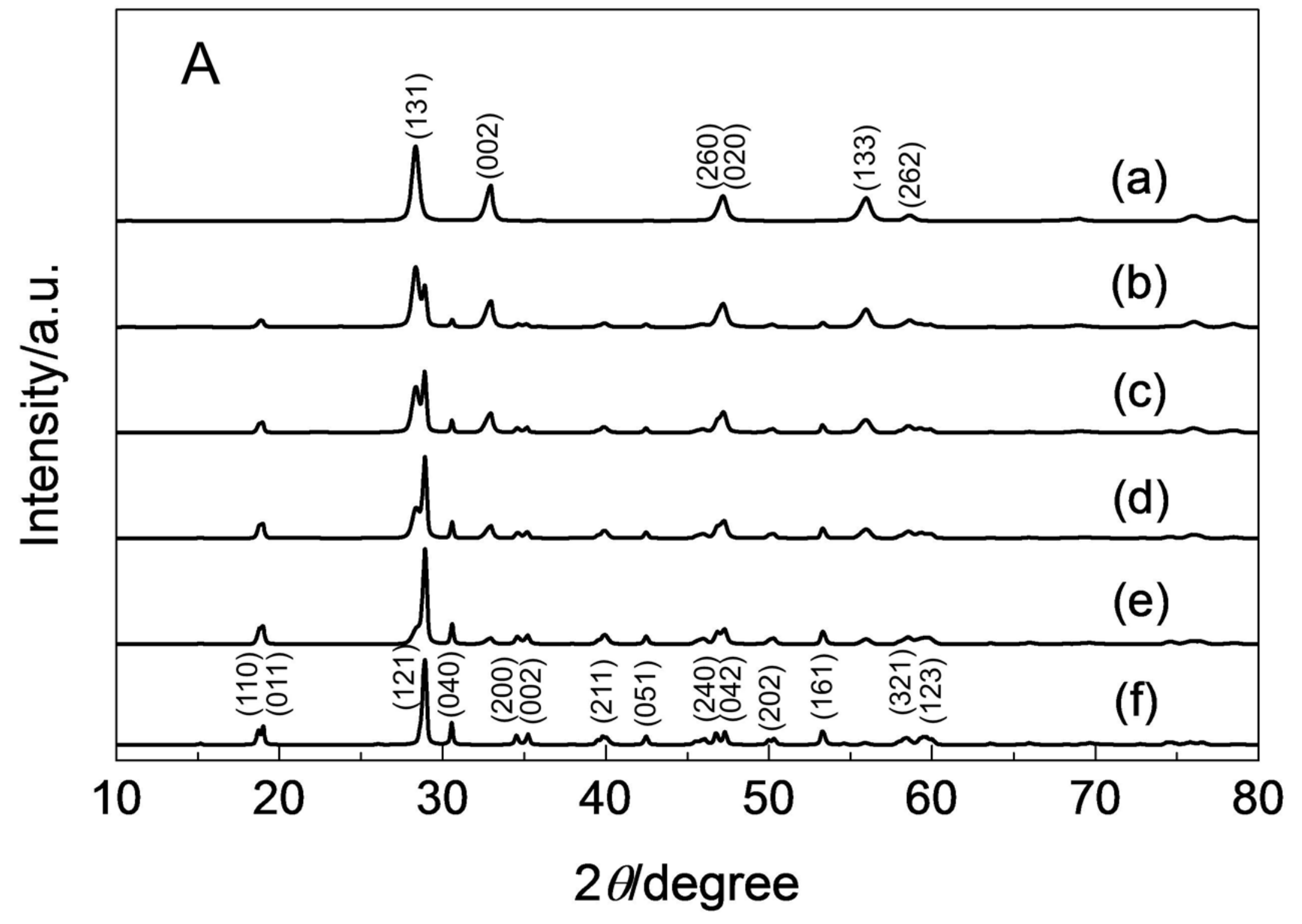

Fig. 3 (A) 


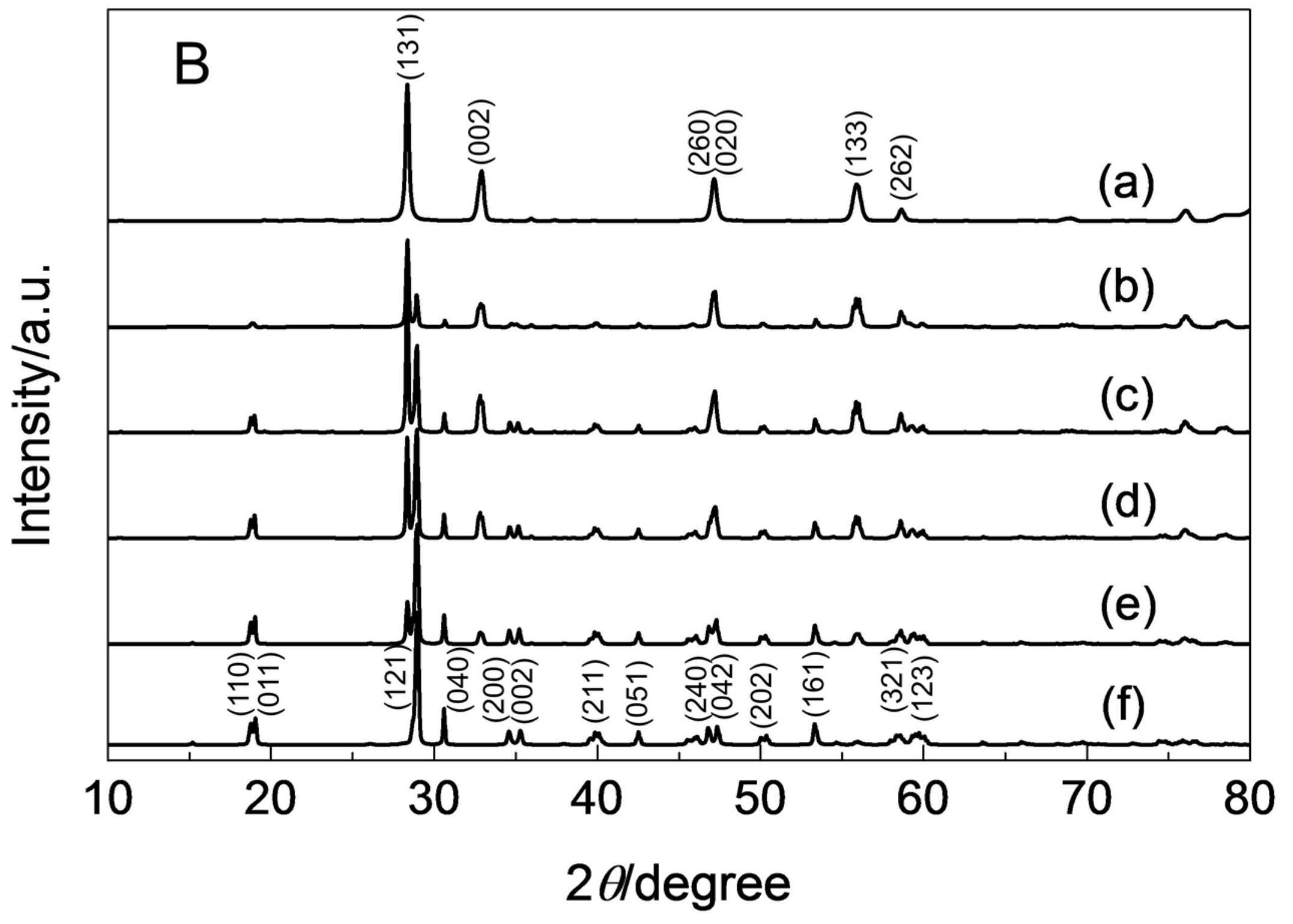

Fig. 3 (B) 


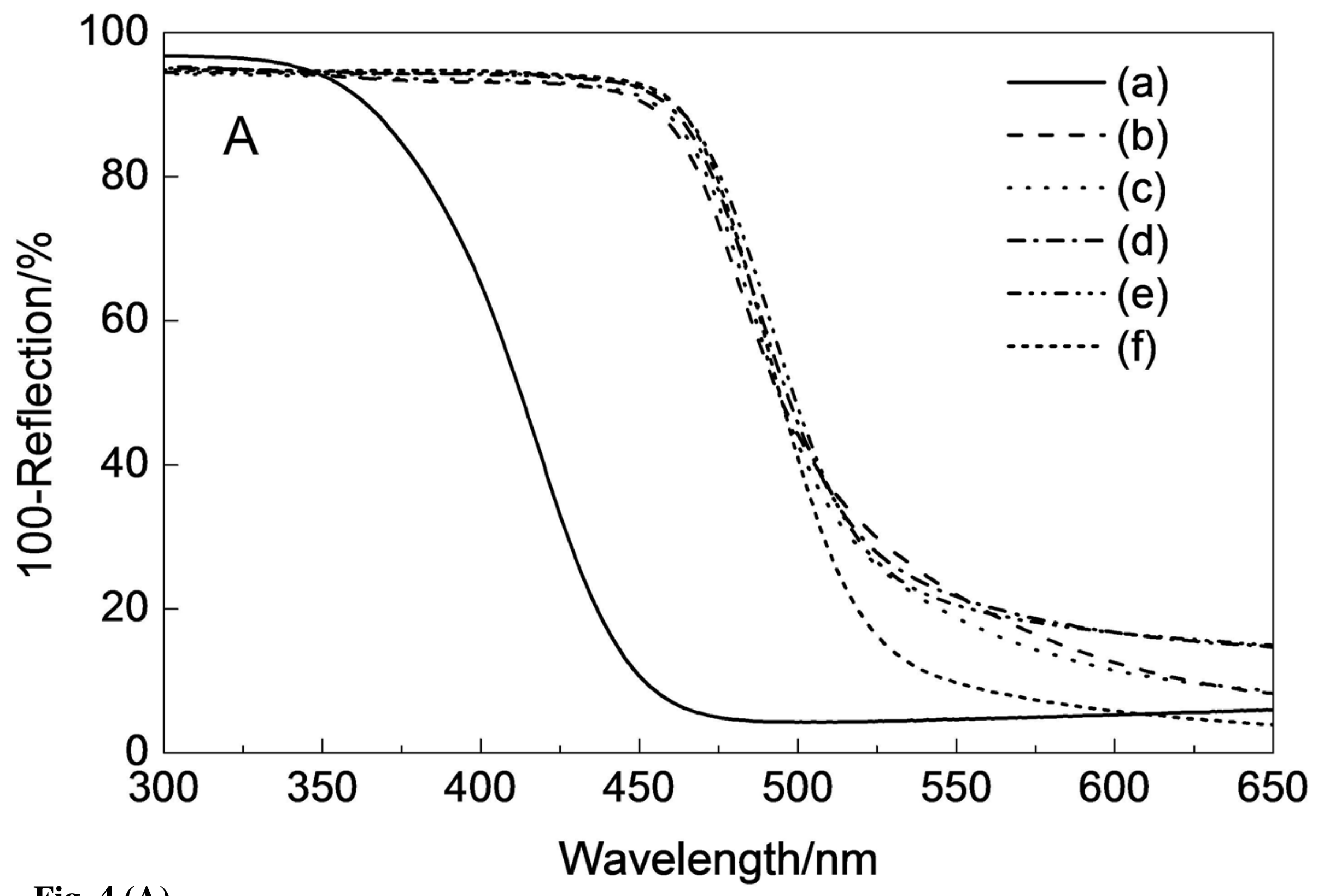

Fig. 4 (A) 


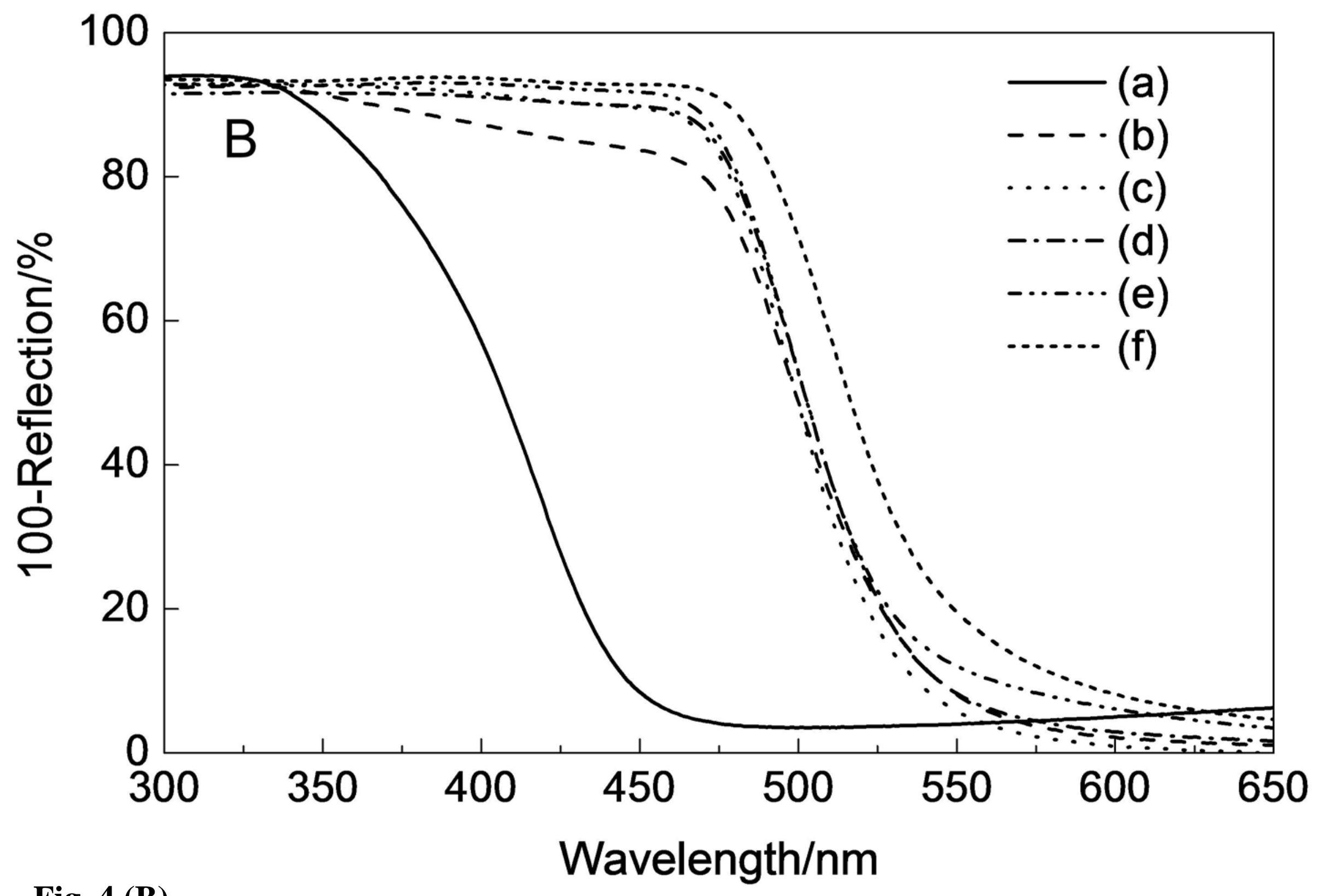

Fig. 4 (B) 


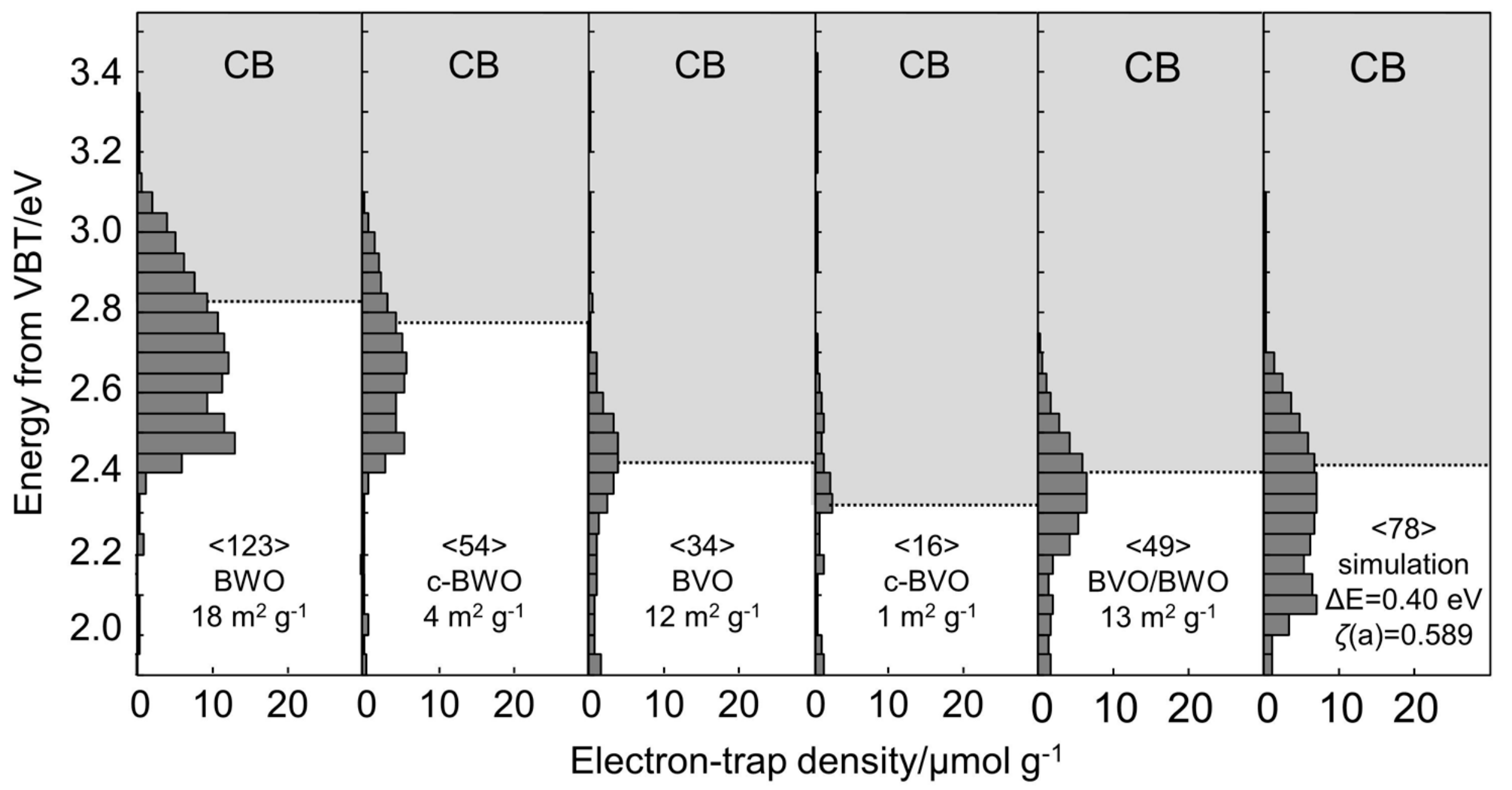

Fig. 5 


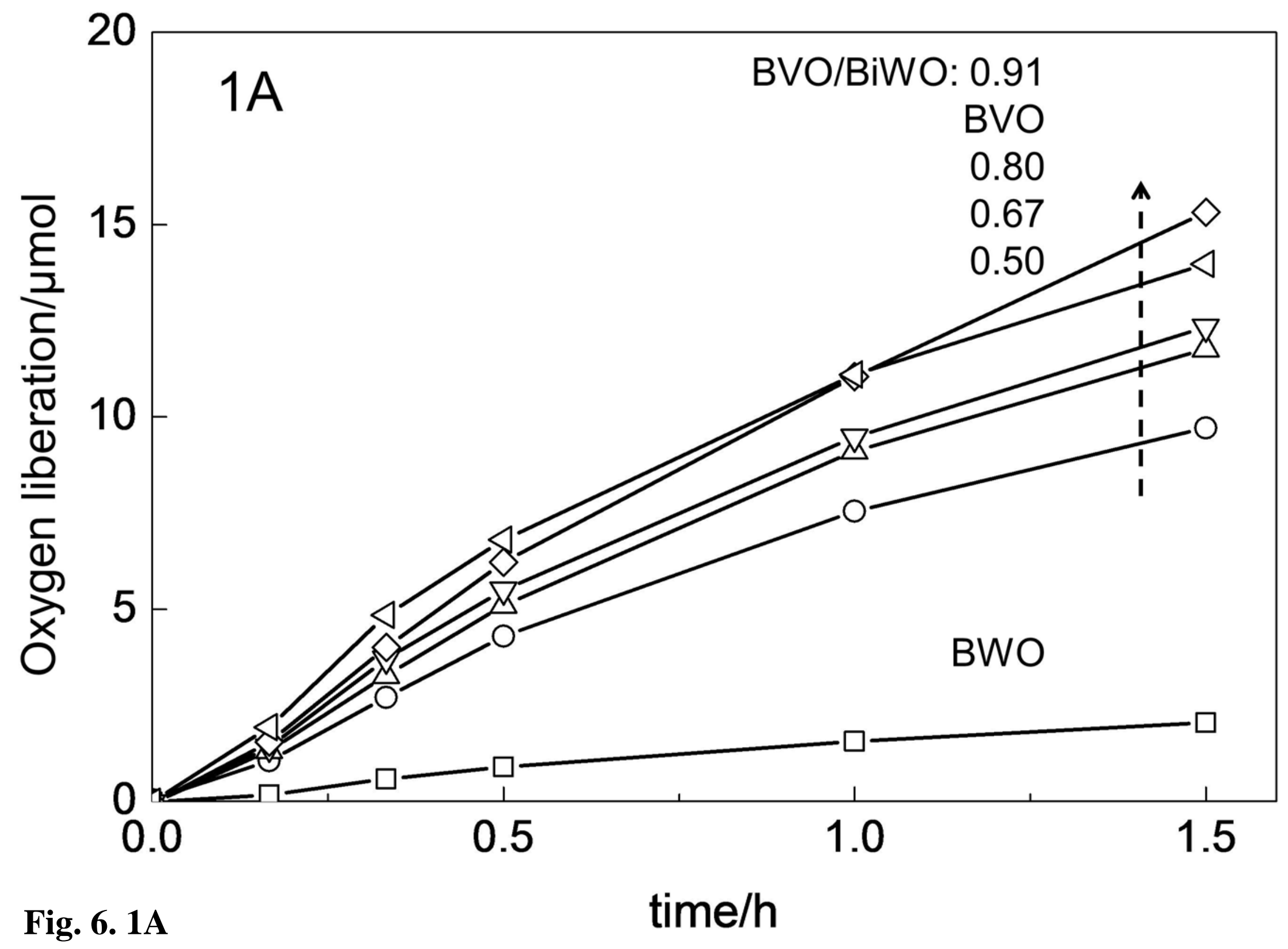




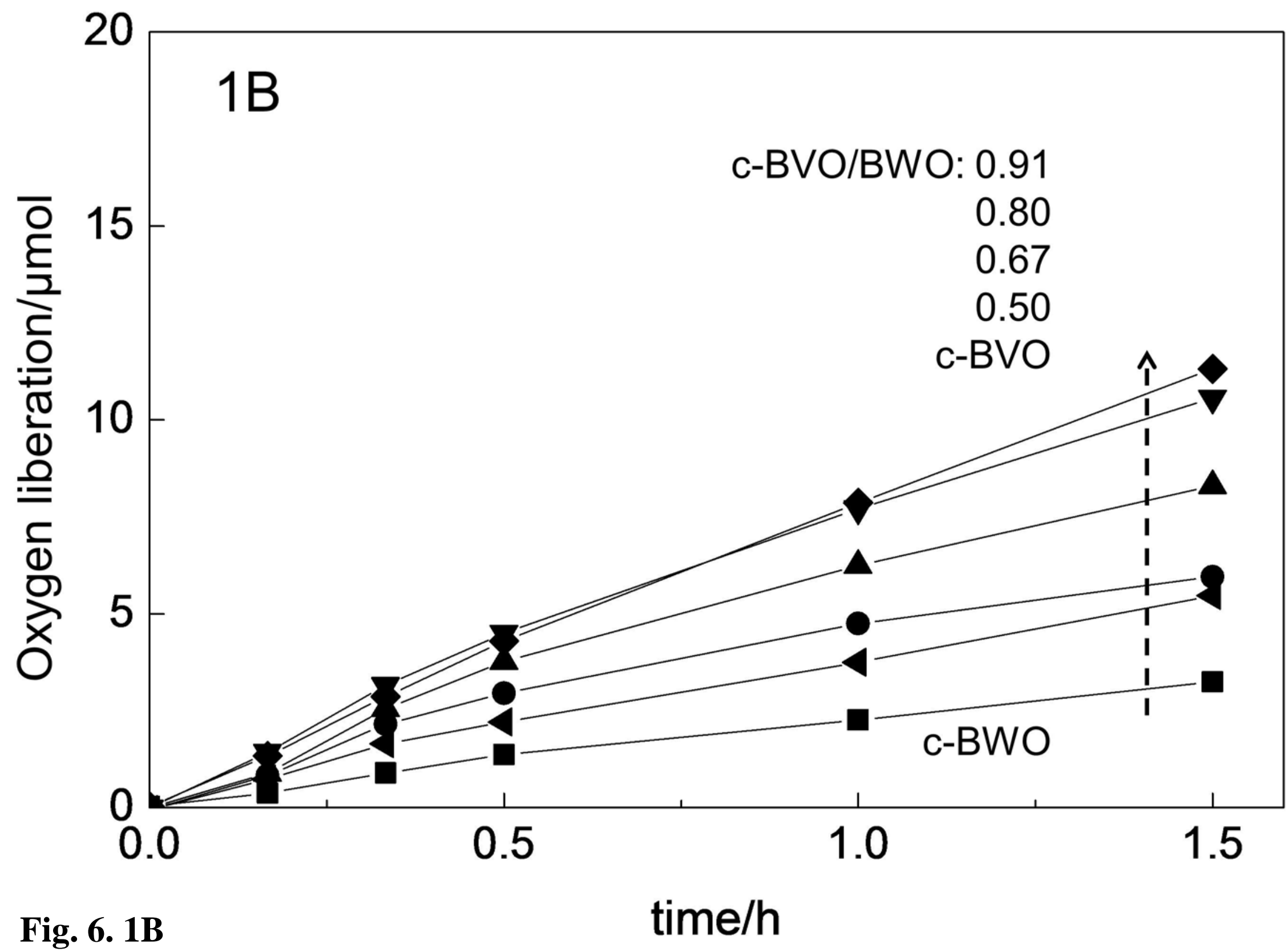




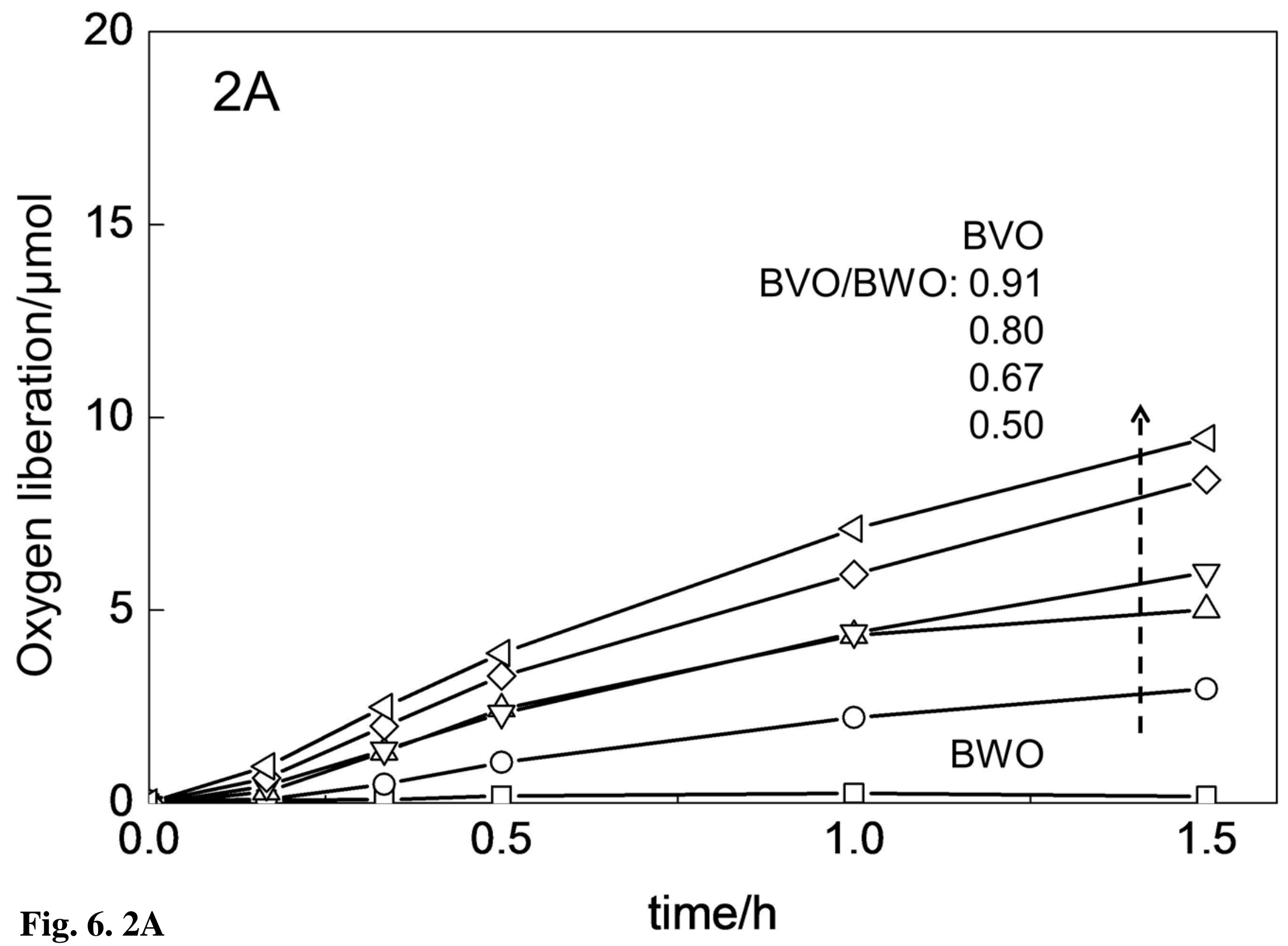




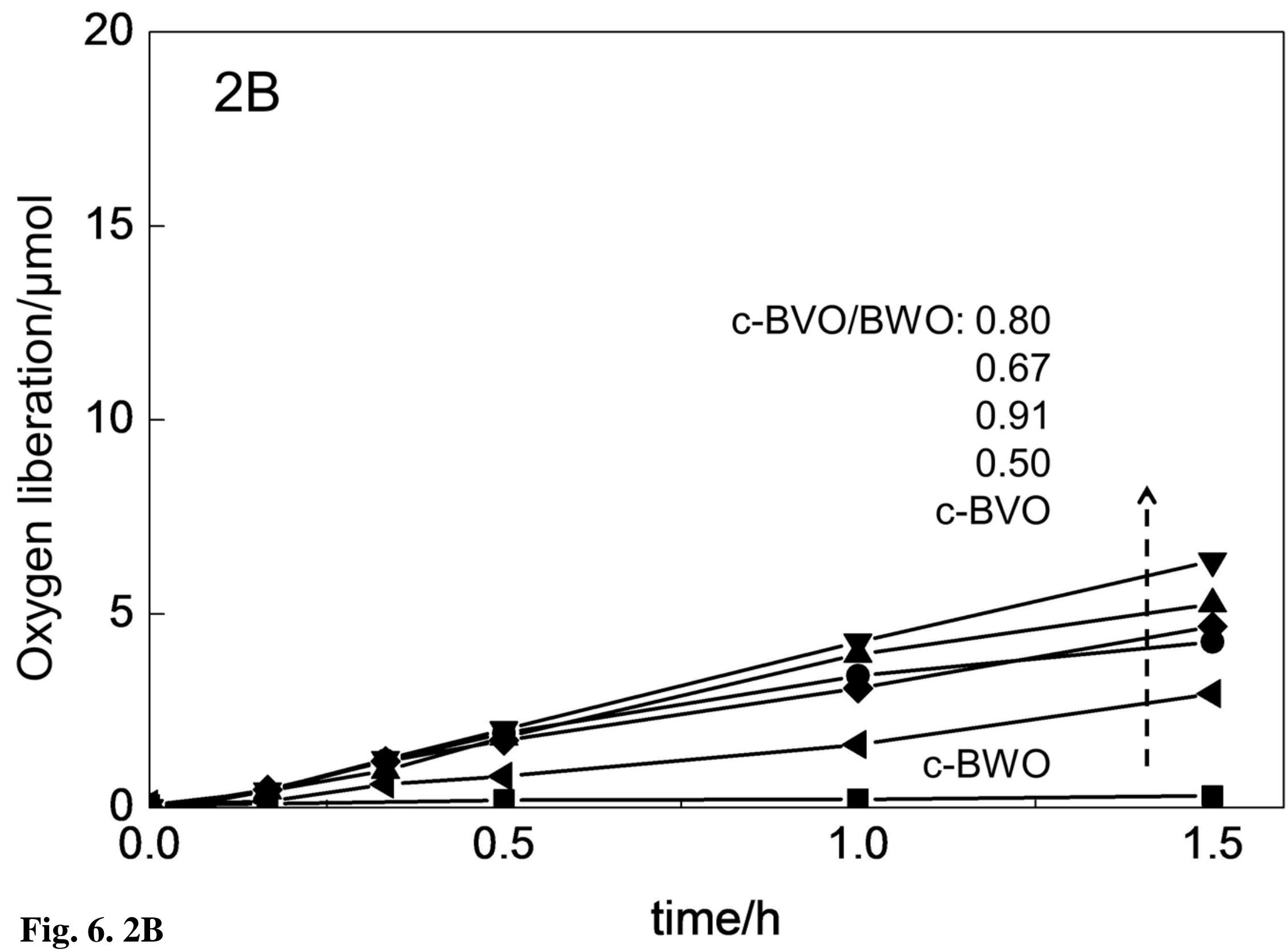




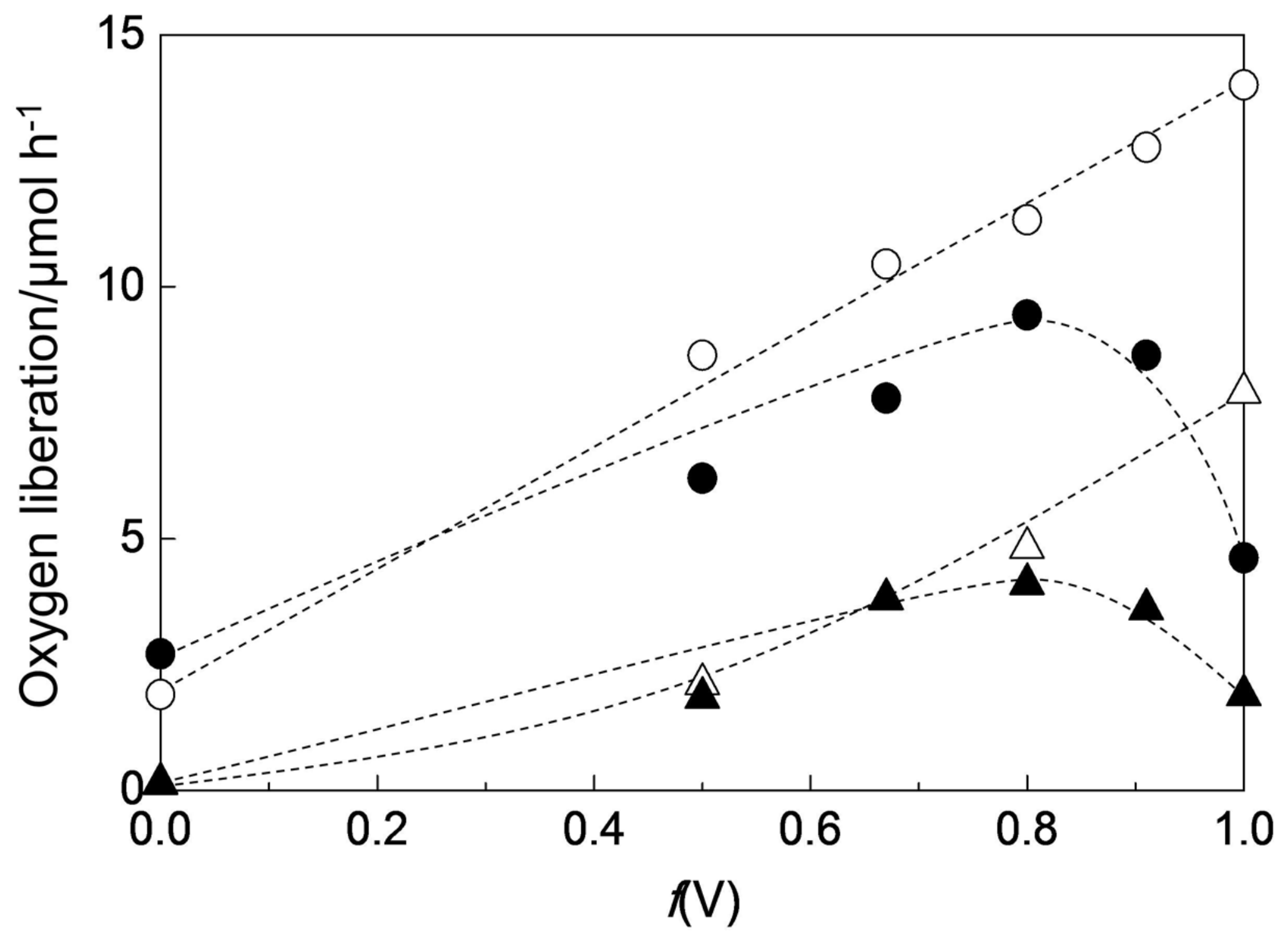

Fig. 7 


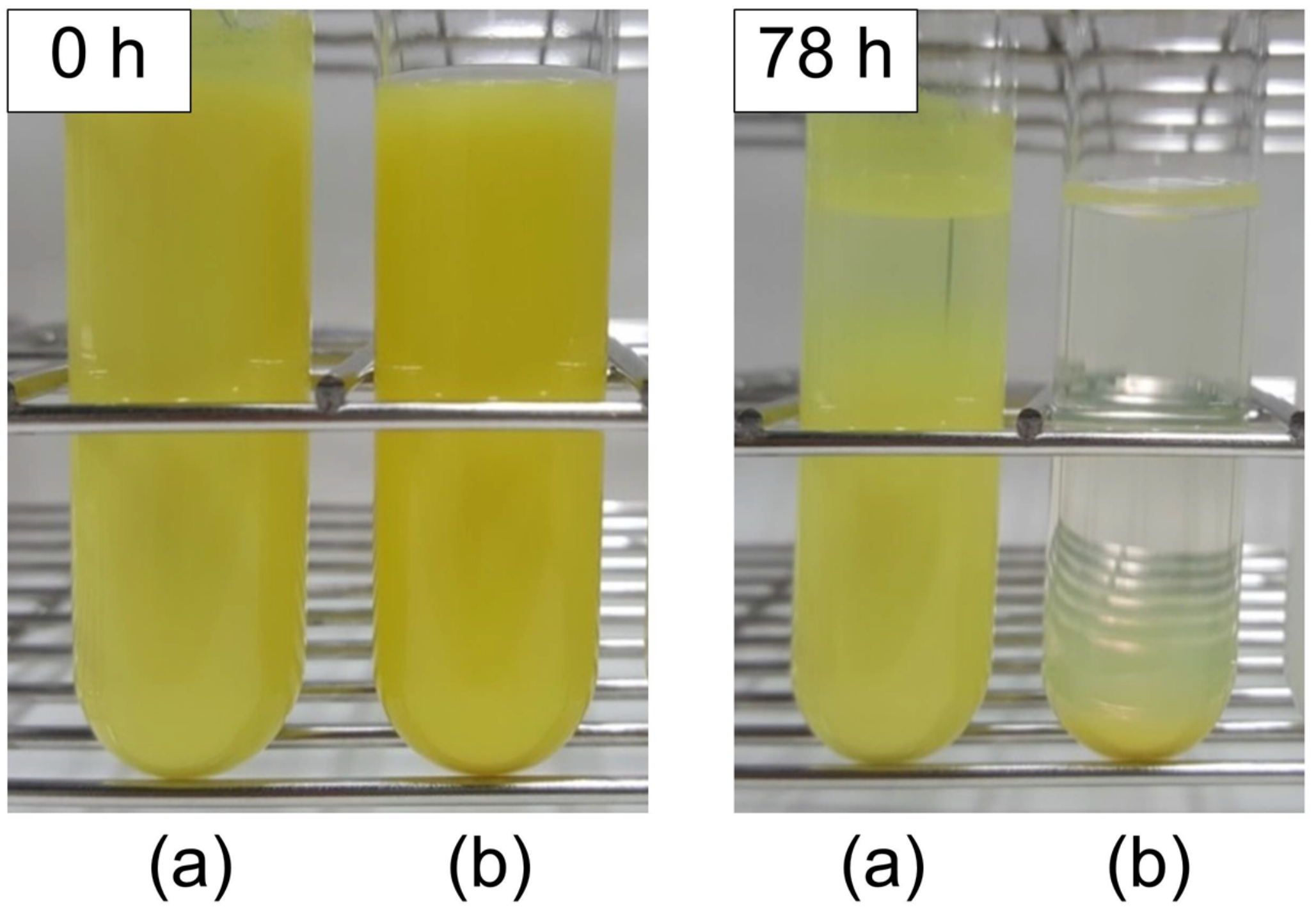

Fig. 8 


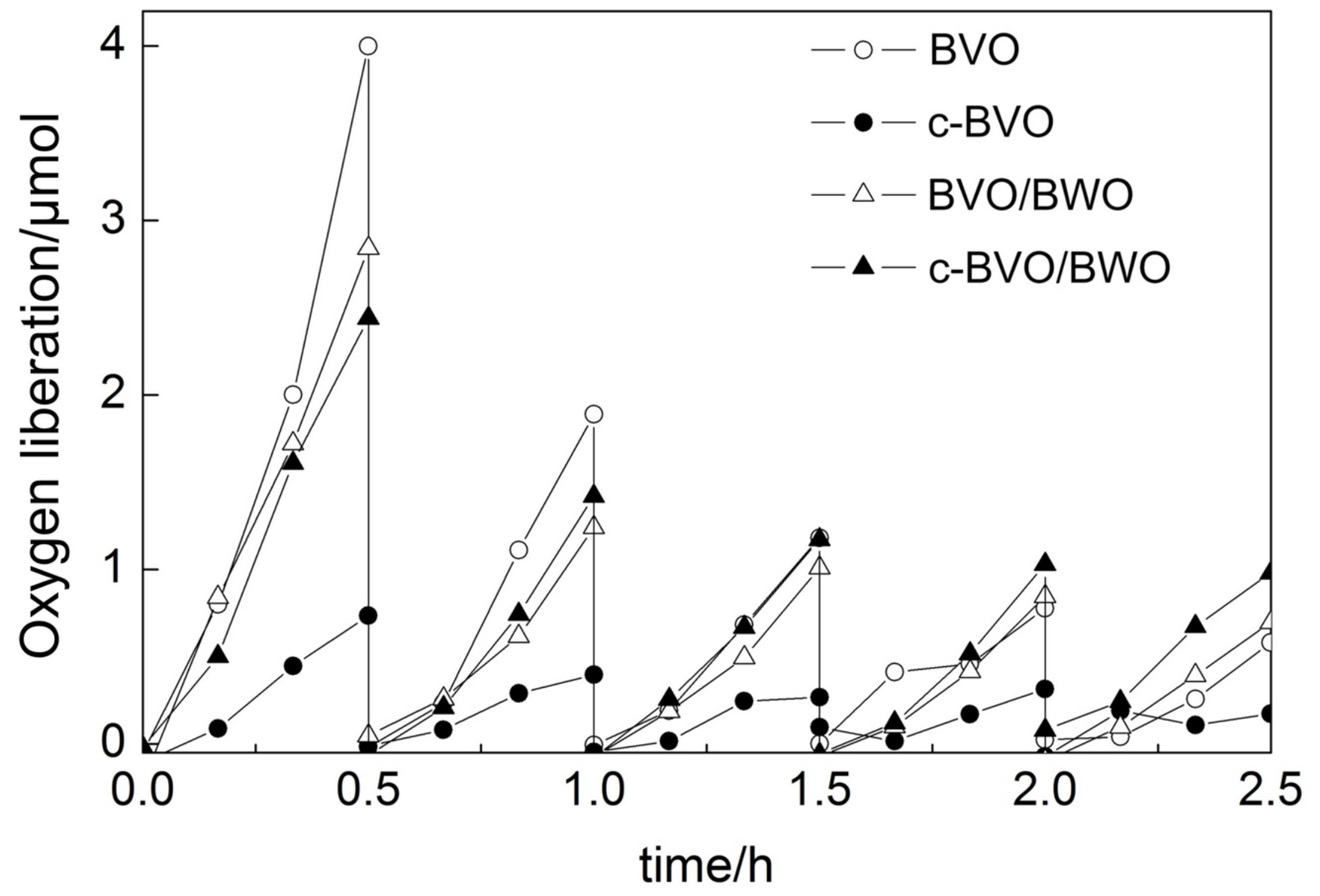

Fig. 9 